\title{
RESPONDING TO SUBLIMINAL CUES: DO IF-THEN PLANS FACILITATE ACTION PREPARATION AND INITIATION WITHOUT CONSCIOUS INTENT?
}

\author{
Ute C. Bayer and Anja Achtziger \\ Universität Konstanz \\ Peter M. Gollwitzer \\ Universität Konstanz; New York University \\ Gordon B. Moskowitz \\ Lehigh University
}

\begin{abstract}
Forming implementation intentions ("If I encounter cue X, then I will perform behavior $\left.Y !^{\prime \prime}\right)$ is postulated to trigger action initiation without further conscious intent once the specified cue is encountered (Gollwitzer, 1999). In two experiments using an injustice paradigm or a categorization task, critical situations (specified in the if-component) were subliminally presented and it was tested whether these situations influenced the preparation (Study 1) and initiation (Study 2) of the planned goal-directed behavior (specified in the then-component). After the subliminal presentation of the critical situations, implementation intention participants showed stronger action preparation and a faster action initiation, as compared to control participants (Study 1) who had not formed any goal intention at all, and compared to participants (Studies 1 and 2) who had only formed goal intentions. These findings suggest that forming implementation intentions leads to automatic action initiation without further conscious intent.
\end{abstract}

Current research on goals recognizes the importance of automatic processes (Förster, Liberman, \& Friedman, 2007; Gollwitzer \& Bargh, 2005; Moskowitz, 2009). For instance, research stimulated by auto-motive theory (Bargh, 1990) assumes that goals are represented mentally and that they can become automatically activated

We thank Sean McCrea for his valuable feedback on an earlier version of this manuscript. We thank the Center for Research on Intentions and Intentionality (Universität Konstanz) and the German Research Foundation (Bonn) for funding this research. Special thanks are due to Juliane Malzacher for her invaluable help in collecting the data for Study 1.

Correspondence concerning this article should be addressed to Ute C. Bayer, FB Psychologie, Universität Konstanz, Universitätsstr. 10, D-78464 Konstanz, Germany.

E-mail: ute.bayer@uni-konstanz.de. 
by contexts in which they were often and consistently pursued in the past. Accordingly, it has been observed that goal striving can be triggered by subliminally presented cues, and that such goal striving may run to completion without the need of conscious involvement (Bargh, Gollwitzer, Lee-Chai, Barndollar, \& Trötschel, 2001; summary by Bargh, 2006). Another example of theories on automatic goal striving is implementation intention theory (Gollwitzer, 1993, 1999). This theory suggests that the starting point of automatic processes is forming an if-then plan by a single act of will. The execution of the if-then plan is postulated to run off automatically without the need of conscious involvement, once the critical cue specified in the if-component is encountered. Automaticity produced by forming if-then plans is therefore referred to as strategic automaticity.

\section{IMPLEMENTATION INTENTIONS AND STRATEGIC AUTOMATICITY}

Gollwitzer (1993, 1999) differentiates between goal intentions and implementation intentions. Goal intentions specify a certain end state one wants to attain and have the format "I intend to attain Z!" Implementation intentions specify when, where, and how one wants to initiate goal-directed action and have the format "If cue X occurs, then I will perform behavior Y!" They create a strong link between a critical cue (i.e., either a situation or an inner state specified in the if-component; Achtziger, Gollwitzer, \& Sheeran, 2008) and a goal-directed behavior (specified in the then-component) by one single conscious act of will. Numerous studies have shown that the attainment of goals strongly benefits from the formation of implementation intentions (for summaries, see Achtziger \& Gollwitzer, 2008; Gollwitzer \& Sheeran, 2006). These beneficial effects of implementation intentions were explained by maintaining that implementation intentions delegate the control of goal-directed responses to critical cues; implementation intentions turn conscious and effortful top-down control of responses by goals into bottom-up control by specified stimuli.

The effects of implementation intentions are assumed to be based on two component processes (Gollwitzer, 1993, 1999). The first process is concerned with the critical cue: It is suggested that forming an implementation intention increases the activation of the mental representation of the critical cue thus heightening its accessibility. As a consequence, the critical cue is more easily detected, readily attended to, and successfully remembered (e.g., Aarts, Dijksterhuis, \& Midden, 1999; Achtziger, Bayer, \& Gollwitzer, under review; Parks-Stamm, Gollwitzer, \& Oettingen, 2007; Webb \& Sheeran, 2007).

The second process is concerned with the goal-directed behavior (i.e., the thencomponent): It is assumed that automatic initiation of the goal-directed behavior occurs as soon as the critical cue is encountered. Accordingly, the initiation of the goal-directed behavior is expected to show efficiency, immediacy, and the absence of conscious intent. The efficiency of action initiation as a consequence of forming implementation intentions was observed in research with samples characterized by action control problems (Brandstätter, Lengfelder, \& Gollwitzer, 2001, Studies 1 and 2; Gawrilow \& Gollwitzer, 2008), dual task paradigms (Brandstätter et al., 2001, Studies 3 and 4), and tasks that burden a person's cognitive capacity (e.g., intelligence tests; Bayer \& Gollwitzer, 2007). Results of these studies suggest that action initiation produced by implementation intentions does not require much cog- 
nitive capacity. Moreover, Cohen, Bayer, Jaudas, and Gollwitzer (2008; Holland, Aarts, \& Langendam, 2006) observed that implementation intentions effectively help to block habitual antagonistic response tendencies, thereby supporting the assumption of immediacy (Gollwitzer \& Brandstätter, 1997, Study 3). Thus, there is sufficient evidence for the assumption that action initiation by implementation intentions fulfills the criteria of efficiency and immediacy.

\section{THE PRESENT RESEARCH: ACTION INITIATION WITHOUT FURTHER CONSCIOUS INTENT}

In implementation intention research the question remains whether the automaticity criterion of the paucity of further conscious intent is also met. Lengfelder and Gollwitzer (2001, Study 2) found some indirect evidence for this assumption with frontal lobe patients, known to have trouble with tasks requiring conscious control of action. These patients benefited from forming implementation intentions by overcoming the hindrance of being deficient in conscious control of action. However, the assumption of action initiation without further conscious intent caused by implementation intentions still requires experimental evidence. In the present studies, we investigated the unconscious preparation and initiation of the goaldirected behavior in the presence of the critical cue specified in the if-component of the implementation intention. We subliminally presented visual stimuli representing the if-component of an implementation intention and assessed action preparation (Study 1) and action initiation (Study 2).

In Study 1, we opted for the goal to complain. We presented the critical situation as a subliminal prime (i.e., the face of an experimenter) in a priming task that demanded the pronunciation of target words. These target words were instrumental to complaining (i.e., instrumental words) or were control words (i.e., describing friendly behaviors). This procedure allowed us to investigate whether words that can be used to enact the goal-directed behavior of complaining were highly accessible when the critical cue specified in the if-component of the implementation intention was presented subliminally. We predicted for the implementation intention condition that instrumental words should show a heightened accessibility if the face of a rude experimenter was presented subliminally as compared to the face of a neutral experimenter; whereas for the control and the goal intention conditions, no such priming effects were expected.

To test whether the actual initiation of the planned behavior occurred without conscious intent once the critical cue was encountered, we also tested the immediacy of performing the goal-directed behavior itself, and not only the accessibility of relevant means (e.g., instrumental words). In Study 2, we used a categorization task in which figures were presented as primes and targets. Participants had to classify the targets as round or angular by pressing a key. We investigated whether the classification performance was accelerated by the subliminal presentation of the critical prime specified in the if-component of the implementation intention. For implementation intention participants, we expected that subliminally presented cues specified in the if-component of the implementation intention should facilitate the initiation of the behavior specified in the then-component. This would provide evidence for action initiation without further conscious intent. Additionally, we inferred that targets that required the same classification response as the 
critical targets should also be categorized faster if the critical prime was presented subliminally compared to a neutral prime, as the critical prime prepares for exactly this classification response.

For goal intention participants, we did not predict that the critical subliminal prime would affect the initiation of the goal-directed behavior, as a goal intention does not create a strong association between the critical cue and the goal-directed behavior; bottom-up control of action by the critical prime thus should not be possible.

\section{STUDY 1: AUTOMATIC PREPARATION OF INTERPERSONAL BEHAVIOR}

Goal and implementation intention participants were insulted by an experimenter (the critical experimenter). Control participants were not insulted. The insult in the goal and implementation intention conditions was manipulated in a manner similar to that used in studies on injustice and retaliation (Miller, 2001). In order to help goal intention participants to respond to the insult, they were asked to set the goal to complain to the critical experimenter about her behavior. In addition, implementation intention participants were asked to form an if-then plan geared at implementing the complaint as soon as they saw the critical experimenter.

The preparation of complaining was indicated by the accessibility of words that can be used to complain (instrumental words). For the implementation intention condition, we predicted that instrumental words should show a heightened accessibility if subliminally primed by the face of the critical experimenter as compared to the face of a neutral experimenter. For the control and the goal intention conditions, no priming-effects (critical vs. neutral face) on the two different types of targets (instrumental vs. control words) were expected.

\section{METHOD}

\section{PARTICIPANTS AND DESIGN}

Sixty-eight female students of a German university participated in the experiment in exchange for monetary compensation equivalent to approximately nine U.S. dollars (age: $M=23.8 ; S D=3.85$ ). The study followed a 2 (Prime: critical vs. neutral face) X 2 (Target: instrumental vs. control words) X 3 (Intention: control vs. goal vs. implementation) mixed-model design, with Prime and Target as within participant variables, and Intention as a between participant variable. We assessed reading latencies (RTs) for target words as the dependent variable.

\section{PROCEDURE}

Participants arrived at the laboratory individually. They were asked to work on two independent experiments (a psychophysiology and a psycholinguistics ex- 
periment) run by two different experimenters. The psychophysiology experiment was described as investigating the physiological effects of looking at landscape pictures (run by a fictitious Experimenter 2) whereas the psycholinguistics experiment (run by Experimenter 1) pertained to latencies in pronouncing words. Before the experiment was started, participants looked at an album containing pictures of four different experimenters currently working at the institute (including Experimenters 1 and 2).

Afterwards, the alleged psychophysiology experiment was started. First, participants had to detect an image flashed on a screen. This procedure of Lieberman and Pentland (1982) was used to determine the individual threshold of subliminal presentation. We used EPTA 5 tachistoscopes from ZAK to establish very short and individually determined subliminal presentation times (i.e., shorter than it is possible by means of a computer due to the computer's refresh rates which are limited to steps of $10 \mathrm{~ms}$, with $10 \mathrm{~ms}$ being the shortest possible presentation time). Thereafter, all participants were informed that physiological data would be recorded while they were looking at landscape pictures. The (fictitious) Experimenter 2 was said to be in a control room, whereas Experimenter 1 would assist by attaching wires-which led to the control room - to the arm of the participant. Finally, Experimenter 1 left the room and the participant read instructions telling her that the assessment of physiological responses would require her to sit completely still.

Afterwards, we presented landscape pictures for 13 seconds each. After 19 landscape pictures, the presentation was interrupted and the participant heard the fictitious Experimenter 2 through an intercom system: "Hello, can you hear me? My name is A. G. I am sitting here in the control room." Goal intention and implementation intention participants were insulted by Experimenter 2 (A.G.): "I am trying to look at your data and I must say that it does not seem that you are sitting quietly. Until now it looks like you are not concentrating on your task, or as if you are not willing to cooperate at all. If you are only here to get some money and are not willing to cooperate, then you will help no one. In the end, it will only make you stay longer and give us bad data!" Control condition participants only heard Experimenter 2 say: "I am looking at your data and it seems that everything is going fine. I will therefore continue collecting the data and you should continue working on the task."

Afterwards, all participants were presented three more landscape pictures. Experimenter 1 returned to remove the wires. In the control condition, she immediately started the psycholinguistics experiment. However, in the goal and implementation intention condition, Experimenter 1 said that she had heard some noise coming from the control room and thus was wondering what had happened. Then, she motivated participants to set the goal intention to complain about the insult: "You do not have to put up with that behavior. If I were you, I would tell her my point of view clearly. You should take matters into your own hands and make clear that nobody can treat participants in this way!" In the goal intention condition, no further comments were made. Implementation intention participants were told: "It is known that it is usually not sufficient to commit oneself to a goal in order to actually attain it. Instead, goals are more often attained if one commits oneself to when one wants to act on them. Therefore, you should commit yourself to complain to the experimenter about her behavior as soon as you see her." All 
participants were reminded who Experimenter 2 was by showing the photo of her to control for the familiarity of her face.

Then, participants started with the alleged psycholinguistics experiment, being told to pronounce presented words as quickly as possible. Afterwards, participants filled out an experimenter evaluation questionnaire and were asked about their suspicions. Goal intention and implementation intention participants were asked about their commitment to their goal intention. Finally, participants were carefully debriefed, thanked, and paid.

\section{MATERIAL}

Primes. The photo of Experimenter 2's face (i.e., the critical experimenter) was presented as the critical prime. As the neutral prime, a photo depicting one of the other experimenters working at the institute but not involved with the current set of studies was used (i.e., neutral experimenter).

Target Words. Eight words instrumental for enacting the goal-directed behavior (i.e., complaining) and eight control words were used as targets. One half of the instrumental words (disgusting, rude, cheeky, conceited), and one half of the control words (patient, friendly, resourceful, clever) were preceded by the critical prime. The other half of these words was preceded by the neutral prime (instrumental words: impertinent, unfair, dumb, nasty; control words: nice, sensitive, fair, generous).

To check whether these words were instrumental or neutral for complaining about the experienced insult, we ran a pretest to rate these words ( $n=24$ female students). Participants read a vignette describing the insult. Then, they were asked whether the 16 words listed above were instrumental for complaining about this behavior on a 9-point answer scale ranging from 1 (= not at all instrumental) to 9 (= very instrumental). Computing means for the words revealed that instrumental words $(M=5.52, S D=1.66)$ were clearly rated as more instrumental for complaining about an insult than control words $(M=2.92, S D=1.77), t(23)=4.28, p<.001$.

Trials. For technical reasons (i.e., changing the slides in a tachistoscope requires a certain amount of time), long SOAs (about $1010 \mathrm{~ms}$ ) were used. A fixation cross appeared in the middle of a projection screen for $2000 \mathrm{~ms}$, followed by a subliminally presented prime. In order to guarantee the subliminal presentation of the primes, the presentation time of the primes was determined individually for each participant $(M=10 \mathrm{~ms}, S D=3.26)$ at the outset of the experiment. This presentation time was then used as the individual presentation time of the primes for this very participant. The prime was followed immediately by a pattern mask presented for $100 \mathrm{~ms}$. After the presentation of the mask, a blank screen appeared for $900 \mathrm{~ms}$, followed by a word for $500 \mathrm{~ms}$. When participants had responded by reading the word aloud, the next trial was started. Subliminal primes and words were paired in a fixed randomized order.

Manipulation Checks and Evaluation of Experimenters' Behavior. Participants were asked for each of the two experimenters: "Are you dissatisfied with how you were treated by the experimenter?"; "Did you think the experimenter had reasonable demands?"; and "How did the experimenter treat you as a participant?" These three questions were answered on 10 -point scales $(0=$ not at all dissatisfied, unrea- 
sonable, and unpleasant; 9 = very dissatisfied, unreasonable, and unpleasant). The next two questions assessed the commitment to the goal to complain in goal intention and implementation intention participants: "Do you intend to complain?" (yes/no/undecided), and "How strongly do you feel committed to complaining?" (9-point answer scale reaching from "not at all" to "strongly").

\section{RESULTS}

\section{SUSPICIONS AND OUTLIERS}

When participants were asked about suspicions concerning the study, three of them reported that they did not believe that the critical experimenter actually existed. Two participants reported that they had been able to see faces prior to the presentation of the words; and one participant claimed that she had seen faces and that one of these faces depicted the critical experimenter. RTs for these five participants were excluded from data analysis. These five participants were about equally distributed across intention conditions. RTs were scrutinized for extreme outliers such that RTs more than 3 standard deviations above and below the mean of each word were excluded. Thus $1.1 \%$ of the RTs were excluded from data analyses.

\section{PRIMING EFFECTS}

A 2 (Prime: critical vs. neutral face) $\times 2$ (Target: instrumental vs. control words) $\times$ 3 (Intention: control vs. goal intention vs. implementation intention) mixed model ANOVA was conducted, with Prime and Target as within participant variables, and Intention as a between participant variable. This revealed a significant Intention $\times$ Prime $\times$ Target interaction effect on RTs, $F(2,60)=6.22, p<.01$. The main effect of Prime was also significant, indicating that RTs for targets presented after the critical prime were longer as compared to the neutral prime, $F(1,60)=3.95, p<$ .05. Furthermore, a significant main effect of Target was observed, $F(1,60)=4.08$, $p<.05$, indicating that RTs for instrumental words were longer than for control words. No other significant effects were observed $(F<1.9, p>.15$; see Figure 1).

To test the hypotheses concerning our intention manipulations, for each of the three intention conditions 2 (Prime: critical vs. neutral face) $\times 2$ (Target: instrumental vs. control words) ANOVAs on RTs were computed separately. In the control condition, a marginally significant main effect of Target was discovered, $F(1$, $18)=3.47, p=.08$. RTs for control targets were shorter than for instrumental targets (instrumental: $M=502, S D=84.85$; control: $M=492, S D=80.59$ ). The factor Prime did not reach significance $(F<1)$, nor did the Prime $\times$ Target interaction effect, $F(1$, 18) $=1.29, p=.27$ (see Figure 1, left side).

In the goal intention condition, the Prime $\times$ Target ANOVA revealed no significant main effects of Target, $F(1,23)=2.48, p=.13$, and of Prime, $F(1,23)=1.50, p$ $=.23$. Also the Prime $\times$ Target interaction effect was not significant $(F<1)$. As expected, having a goal intention to complain did not facilitate access to instrumen- 

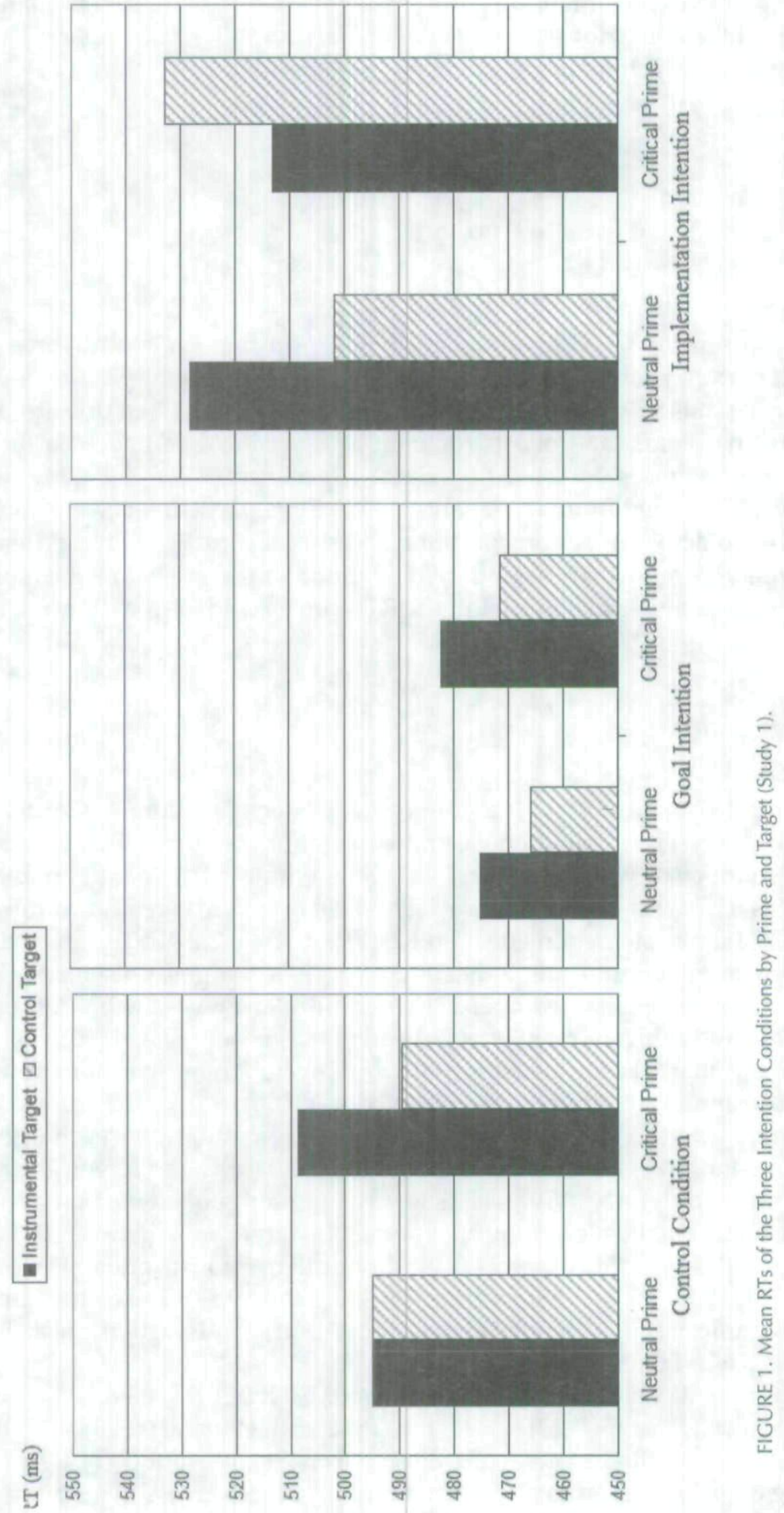
tal target words compared to control words when the critical face was presented as a prime (see Figure 1, middle part).

In the implementation intention condition, the Prime $\times$ Target ANOVA revealed a significant interaction effect, $F(1,19)=13.99, p<.001$. The main effect of Target did not reach significance $(F<1)$, nor did the main effect of Prime, $F(1,19)=1.73$, $p=.20$. Furthermore, planned $t$-tests revealed that instrumental words subliminally primed by the critical prime $(M=513, S D=82.11)$ were responded to faster than instrumental words primed by the neutral prime $(M=528, S D=81.78), t(19)$ $=1.92, p=.03$ (one-tailed). In addition, control words subliminally primed by the critical prime $(M=532, S D=70.16)$ were responded to significantly more slowly than when subliminally primed by the neutral prime $(M=501, S D=80.71), t(19)$ $=3.29, p<.01$ (see Figure 1, right side). Finally, after the presentation of the critical prime, shorter RTs were observed for instrumental words $(M=513, S D=82.11)$ as compared to control words $(M=532, S D=70.16), t(19)=2.39, p<.05$. The reverse was true after the presentation of the neuiral prime (instrumental words: $M=528$, $S D=81.78$; control words: $M=501, S D=80.71), t(19)=2.43, p<.05$.

\section{FURTHER ANALYSES}

First, we checked for participants' goal commitment. When asked whether participants intended to complain, no differences emerged between goal and implementation intention participants, $\chi^{2}(2, N=42)=3.36, p=.15$. Thus, no significant increase in goal commitment as a consequence of forming an implementation intention was observed. The question concerning participants' commitment to complaining also did not reveal a significant difference between goal $(M=4.24, S D=$ 2.96) and implementation intention participants $(M=4.70, S D=2.92), F<1$.

Second, we analyzed the evaluation of the experimenters' behavior. The three items evaluating the two experimenters' behavior were highly correlated (Cronbach's $=.87$ ), and thus an evaluation index was created by computing the mean of the items. An Experimenter $\times$ Intention ANOVA with repeated measures on the first factor revealed a significant main effect of Experimenter, $F(1,58)=155.16, p<$ .001 , and a significant Experimenter $\times$ Intention interaction effect, $F(2,58)=36.99$, $p<.001$. A subsequent ANOVA on the evaluation of the critical experimenter revealed a significant main effect, $F(2,58)=38.13, p<.001$. Control condition participants had a mean close to zero $(\mathrm{M}=.74, \mathrm{SD}=.96)$, indicating a positive evaluation of the experimenter. Goal intention participants $(M=4.74, S D=2.46)$ evaluated the critical experimenter more negatively than control participants, and this difference was even more pronounced with implementation intention participants $(M=6.30, S D=2.13), t(41)=2.21, p<.05$. When we analyzed the evaluation of the neutral experimenter, participants in the three conditions did not differ (control condition: $M=.66, S D=.90$; goal intention condition: $M=.47, S D=.79$; implementation intention condition: $M=.57, S D=.78), \mathrm{F}<1$. By computing $t$-tests comparing the evaluation of the two experimenters for each of the three conditions, we observed that control participants evaluated both experimenters equally positive, $t<1$. However, the critical experimenter was evaluated more negatively than the neutral experimenter by goal intention, $t(22)=8.14, p<.001$, and implementation intention participants, $t(19)=11.45, p<.001$. 
Due to these results, we wondered whether the different RTs for critically vs. non-critically primed target words between the three conditions were influenced by the different evaluations of the critical experimenter. We computed an ANCOVA, using the between factor Intention, the within factors Prime and Target, and the Evaluation of the critical experimenter as a covariate. No significant influence of Evaluation on RTs was observed, $F<1$, but again a significant Intention $\times$ Prime $\times$ Target interaction effect emerged, $F(2,57)=4.40, p<.05$. Despite controlling for the evaluation of the critical experimenter's behavior, the pattern of results stayed the same. This suggests that the evaluation of the critical experimenter's behavior was not responsible for the observed pattern of RTs.

\section{DISCUSSION}

Implementation intention participants evidenced shorter RTs for instrumental words as compared to control words-given that these words were subliminally primed with the face of the critical experimenter (i.e., the if-component of the implementation intention). The reverse pattern was observed (i.e., shorter RTs for control as compared to instrumental words) when these words were subliminally primed with a neutral face. Implementation intentions did not support the preparation of complaining in general, as a heightened accessibility of instrumental words was found only if the critical cue (i.e., the face of the critical experimenter) was used as a prime.

This cross-over interaction pattern of the RTs in the implementation intention condition speaks for the preparation of the behavior of stating a complaint once the critical experimenter is encountered--without the necessity of conscious intent. Remember that we made every effort to ensure that participants were not able to consciously perceive the primes: Individually determined thresholds (the mean threshold was as low as $10 \mathrm{~ms}$ ) were used for each participant to guarantee that the presentation of the primes was indeed subliminal, and the three participants who noticed that faces were used as primes (note that only 1 of them recognized the face of the critical experimenter) were excluded from the data analysis. One might also wonder whether the results of the implementation intention condition could be alternatively explained by a more negative evaluation of the critical experimenter's behavior in the implementation intention condition. However, when we statistically controlled for this we did not observe a significant influence on RTs.

In the goal intention condition, we did not observe the significant Prime $\times$ Target interaction that was found in the implementation intention condition. Apparently, goal intentions do not allow for automatic preparation of goal-directed behavior even if one strongly intends to enact this behavior. Note that goal intention participants reported the same strength of the goal commitment to complain as implementation intention participants.

Still, one might want to argue that the instrumentality of the target words used in the present study was confounded with valence, and that we only studied the preparation of action in the sense of heightened cognitive accessibility of the means (words). Therefore, in Study 2 we presented primes and targets that were neither negative nor positive and we investigated whether the subliminal presentation of the cue specified in the if-component of an implementation intention affects the actual performance of the goal-directed behavior. 


\section{STUDY 2: AUTOMATIC INITIATION OF CATEGORIZATION RESPONSES}

A strong test of the assumption that implementation intentions initiate goal-directed responses without conscious intent requires measuring how fast the goal-directed response is initiated when primed subliminally by the if-component. Therefore, participants in Study 2 were all assigned the task to categorize geometrical figures as either angular or rounded as quickly and accurately as possible by pressing a key. Implementation intention participants furnished this goal intention with an if-then plan. Goal intention participants were instead asked to familiarize themselves with the critical targets. As dependent variable, RTs for the classification responses were measured.

We predicted that the categorization response specified in the then-component of the implementation intention for the critical target (i.e., pressing the right key when a triangle is presented) should be facilitated if the critical cue (i.e., the triangle) was presented as a subliminal prime. Furthermore, responses to congruent targets (i.e., all of the angular figures) requiring the same categorization response (i.e., pressing the right key), should also be facilitated when the critical cue was subliminally presented. This prediction was based on the assumption that the heightened readiness to perform the planned response caused by the presentation of the critical prime (i.e., the triangle) should facilitate performing this response no matter whether it was required by the cue specified in the if-component of the implementation intention or by a cue of the same category (i.e., a different angular target than the triangle). Finally, for the goal intention condition, we did not predict that the subliminally presented critical prime should affect categorization responses for the targets as no links between a critical cue (i.e., the triangle) and the respective classification response (i.e., pressing the right key) were formed.

\section{METHOD}

\section{PARTICIPANTS AND DESIGN}

Forty-six students ( 26 female) at a German university enrolled in different fields of studies (age: $M=22.74$ years; $S D=2.36$ ) participated in the experiment in exchange for monetary compensation equivalent to approximately six U.S. dollars.

The study followed a 2 (Prime: critical vs. neutral figure) $\times 3$ (Target: critical vs. congruent vs. incongruent figures) $\times 2$ (Intention: goal vs. implementation) mixedmodel design, with Prime and Target as within participant variables, and Intention as a between participant variable. For counterbalancing reasons, two further between-participant factors were varied: position of the response keys (left/right) and type of critical prime (triangle vs. circle). As dependent variable, RTs for the categorization of the targets were measured. When we tested whether there were effects of response key position (left/right) and type of critical prime (circle vs. triangles), no significant effects were detected (all $F s<1$ ). Therefore these factors are not discussed any further. 
TABLE 1. Two Sets of Counterbalanced Stimuli of Study 2

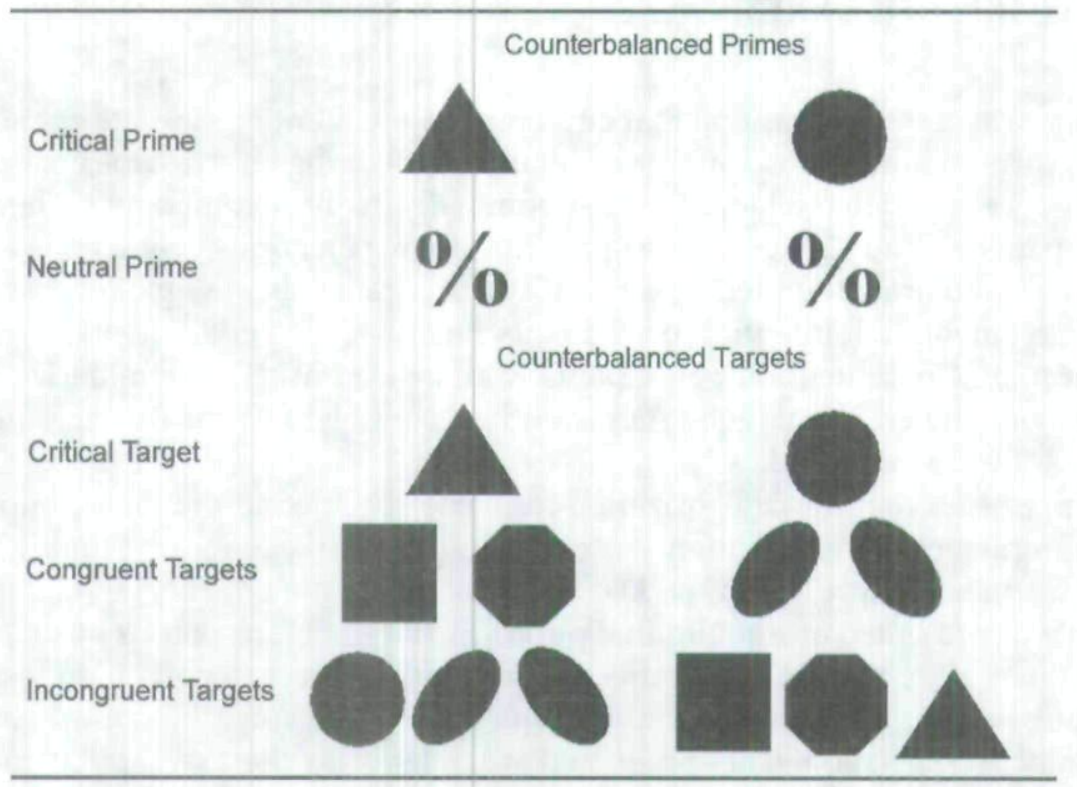

\section{PROCEDURE}

Participants individually took part in an experiment on traffic regulation. The experimenter explained that individual differences concerning perceptual capability would be tested first. Individual thresholds were determined by the same procedure as in Study 1, with the exception of presenting geometrical figures instead of faces. Thus, we guaranteed that the primes could no longer be perceived consciously.

All participants were then told that we investigated the visibility of geometrical figures. The task was to classify the figures as quickly as possible by pressing the respective key. Prior to this task, they were given either goal or implementation intentions.

To introduce the intentions, and to heighten accessibility of the critical target, participants were told the critical figure was central to the experiment's concern with traffic regulation (its visibility in a traffic sign). They were instructed to begin with a task focused on the figure. Goal intention participants were told to draw the figure three times on a sheet of paper to familiarize themselves with it (for a similar procedure see Brandstätter et al., 2001; Lengfelder \& Gollwitzer, 2001); thus controlling for salience effects between the goal and the implementation intention condition. However, implementation intention participants were asked to form the implementation intention: "If I see a triangle, then I will press the right key particularly fast!" ${ }^{\prime \prime}$ This plan was repeated silently three times. Thereby, the critical figure was strongly linked to the respective categorization response.

1. For counterbalancing reasons there were four different implementation intention instructions: "If I see a triangle (circle), I will press the right (left) key particularly fast!" 
Primes and Targets. Either the critical or the neutral prime was presented subliminally in each of the 360 trials. For counterbalancing reasons, the critical prime was either a circle or a triangle (see Table 1, upper line). Six geometrical figures were presented as targets (see Table 1). These targets fell into three categories depending on the kind of response they required: critical targets, congruent targets, and incongruent targets. The critical targets were either the triangle or the circle, whereas congruent targets were other angular or rounded figures that participants were asked to categorize in the same way as the critical target. Incongruent targets required a different categorization response than the critical and congruent targets.

Trials. All stimuli were presented by the same tachistoscope used in Study 1. In each trial, a fixation cross appeared on the screen for $1000 \mathrm{~ms}$. After a delay of $900 \mathrm{~ms}$, a prime was presented subliminally with presentation times determined individually for each participant prior to the experiment $(M=11.29 \mathrm{~ms}, S D=2.74)$. The prime was immediately followed by a pattern mask lasting for $100 \mathrm{~ms}$ and a blank screen for $900 \mathrm{~ms}$. Finally, the target appeared for $2000 \mathrm{~ms}$ (or until a key was pressed; see Figure 2). Participants completed 360 trials; primes and targets were presented in a fixed random order.

Manipulation Check. After the categorization task, participants completed a questionnaire. Three items evaluated task involvement (e.g., "How concentrated did you work on this task?"; "How much effort did you exert on this task?"; and "How much fun did you have?"). Two further items assessed goal commitment ("How important was it for you to categorize the figures fast and accurately?" and "How committed did you feel to strive for this goal?"). Answers were given on 10-point scales (from $0=$ not at all to $9=$ very much). Afterwards, participants were debriefed, thanked, and paid.

\section{RESULTS}

\section{SUSPICIONS AND OUTLIERS}

RTs of more than 3 standard deviations above or below the mean in each category were excluded, as well as wrong responses. Participants who had more than $20 \%$ missing data due to missing responses, wrong responses, and responding too slowly/quickly were to be excluded; we eliminated the data of 5 participants. One participant reported being able to see a triangle prior to the mask and was thus excluded from data analysis. The final data analyses were based on a data set from which $4.8 \%$ of the trials had been eliminated.

\section{PRIMING EFFECTS}

A 2 (Prime: critical vs. neutral figure) X 3 (Target: critical vs. congruent vs. incongruent figures) $\times 2$ (Intention: goal vs. implementation) mixed-model ANOVA was conducted, with Prime and Target as within participant variables, and Intention as a between participant variable. The ANOVA revealed the expected significant Intention $\times$ Prime $\times$ Target interaction, $F(2,80)=3.04, p<.05$, and a significant 


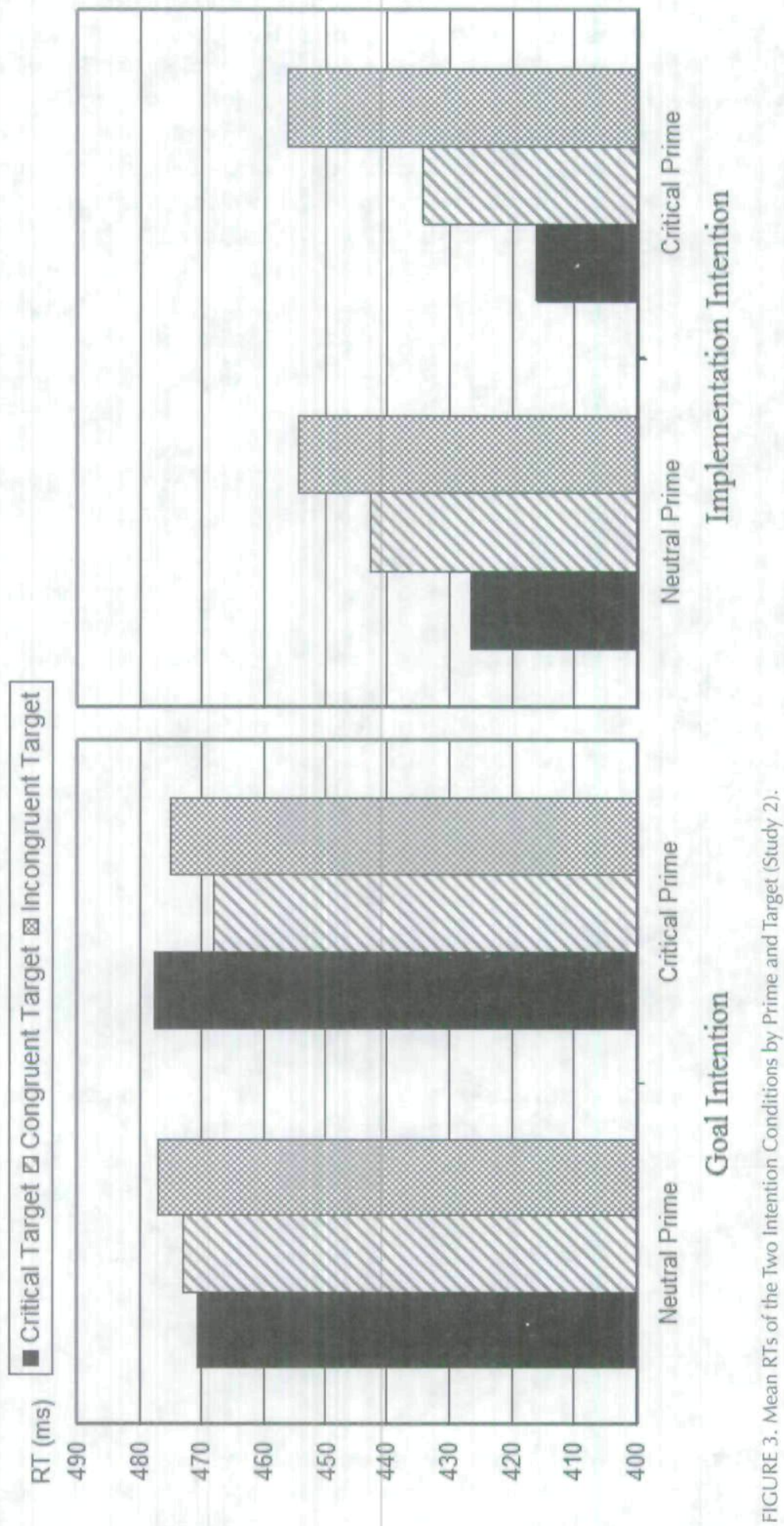


Intention $\times$ Target interaction, $F(2,80)=4.79, p<.01$. Intention did not reach significance, $F(1,40)=2.28, p=.14$, nor did Prime, $F(2,40)=2.40, p=.13$, but there was a significant main effect of Target, $F(2,80)=5.92, p<.01$. No other effects reached significance, $F \mathrm{~s}<1.23$, $p \mathrm{~s}>.30$ (see Figure 3 ).

We analyzed the Intention $\times$ Prime $\times$ Target interaction further: In the goal intention condition, the Prime $\times$ Target interaction did not reach significance, $F(2$, $42)=1.70, p=.19$, nor did any of the main effects (all $F$ s $<1$, see Figure 3, left side). As expected, the subliminal primes did not have any effects on goal intention participants' categorization responses.

In the implementation intention condition a significant Prime $\times$ Target interaction was observed, $F(2,38)=3.14, p<.05$. This interaction qualified a significant main effect of Prime, $F(1,19)=6.11, p<.05$, and of Target, $F(2,38)=7.13, p<.01$ (see Figure 3, right side). Supporting our hypotheses, participants were significantly faster in categorizing critical targets preceded by the critical prime $(M=416, S D=$ 94.42) than in categorizing critical targets preceded by the neutral prime $(M=426$, $S D=86.83), t(19)=2.18, p<.05$. Moreover, we observed that critical targets $(M=$ $416, S D=94.42)$ were classified faster than congruent targets $(M=434, S D=71.59)$, $t(19)=2.23, p<.05$, and incongruent targets $(M=456, S D=78.71), t(19)=3.19, p<$ .01 , if the critical prime preceded these targets.

Further supporting our hypotheses, congruent targets preceded by the critical prime $(M=434, S D=71.59)$ were classified significantly faster than congruent targets preceded by the neutral prime $(M=443, S D=77.16), t(19)=2.66, p<.05$. Furthermore, responses to congruent targets $(M=434, S D=71.59)$ were significantly faster than responses to incongruent targets $(M=456, S D=78.71)$, if the critical prime was presented, $t(19)=2.50, p<.05$. Apparently, when the classification response specified in the then-component of the implementation intention was requested by other targets than the critical target, the critical subliminal prime managed to facilitate the classification response.

Analyzing RTs after the presentation of the neutral prime, we replicated findings of former research (e.g., Brandstätter et al., 2001). The implementation intention facilitated categorization responses to those targets that were specified in the ifcomponent $(M=426, S D=86.83)$ compared to congruent targets $(M=443, S D=$ $77.16), t(19)=2.23, p<.05$, and incongruent targets $(M=455, S D=73.80), t(19)=$ $2.78, p<.01$.

\section{FURTHER ANALYSES}

The two goal commitment items correlated significantly $(r=.51, p<.01)$ and their answers were averaged. All participants reported a strong goal commitment (goal intention condition: $M=7.28, S D=1.24$; implementation intention condition: $M=$ $6.84, S D=1.32$ ) that did not differ between conditions, $F(1,39)=1.20, p=.28$. Apparently, forming an implementation intention did not lead to an increased goal commitment.

For the questions of how concentrated (goal intention condition: $M=5.05, S D=$ 1.80; implementation intention condition: $M=5.74, S D=1.69$ ) and how effortful participants worked on the task (goal intention condition: $M=4.43, S D=2.13$; implementation intention condition: $M=4.84, S D=2.14$ ), no significant differences were observed between conditions, $F(1,39)=1.54, p=.22$, and $F<1$. However, 


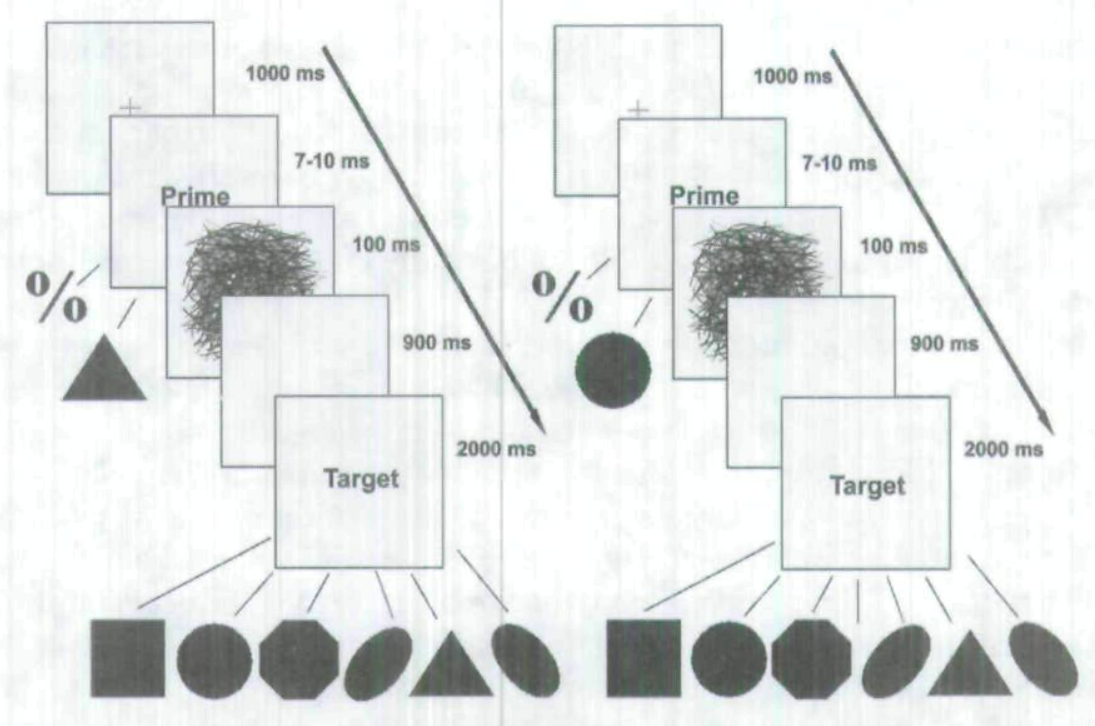

FIGURE 2. Sequence of Primes and Targets in a Trial (Study 2).

implementation intention participants reported significantly more fun than goal intention participants (goal intention condition: $M=2.62, S D=1.99$; implementation intention condition: $M=3.94, S D=1.98), F(1,39)=4.46, p<.05$. Possibly implementation intention participants experienced more flow (Csikszentmihalyi, 2000) during task performance.

\section{DISCUSSION}

In line with previous implementation intention research (Brandstätter et al., 2001), we found that categorization responses to a critical target (i.e., the cue specified in the if-component) were significantly faster than to nonspecified targets. More importantly, presenting this critical cue as a subliminal prime speeded the respective categorization response specified in the then-component compared to the subliminal presentation of a neutral prime. Apparently, the subliminal occurrence of the cue specified in the if-component of an implementation intention triggered the response specified in the then-component without conscious intent. When this response was required by a new situation (i.e., by the congruent targets), its execution was still accelerated suggesting that the observed speed-up effects were not simply due to the facilitated perception of the critical cue. These effects were not observed in trials in which the neutral prime was presented. The findings thus support our prediction that the occurrence of the critical cue facilitates the initiation of the response specified in the then-component of an implementation intention. As the critical prime was presented subliminally, we can conclude that speeded response initiation by critical cues does not require conscious intent. 
There was no inhibition of responses to incongruent targets after the presentation of the critical primes. This result is in line with findings in cognitive psychology. The inhibition of categorization responses to targets by dissimilar primes and the facilitation of categorization responses to targets by similar primes is only observed if very short SOAs are used (e.g., Eimer \& Schlaghecken, 2003). As we used very long SOAs (i.e., about $1000 \mathrm{~ms}$ ), no inhibition of responses to incongruent targets was to be expected.

The priming effects on the classification responses for critical and congruent targets in the implementation intention condition could not be observed in the goal intention condition, despite the fact that the salience of the critical target was heightened due to a familiarization manipulation in the latter condition. This suggests that the strategic automaticity created by implementation intentions is not only a consequence of heightened activation of the critical cue, but also is due to the creation of a strong link between this cue and the planned response. Moreover, this finding also indicates that the observed priming effects in the implementation intention condition cannot be due to a mere category based sequential priming effect (Bargh \& Chartrand, 2000).

\section{GENERAL DISCUSSION}

The strong effects of implementation intentions are explained by automatic action initiation processes that are assumed to be immediate, efficient, and not requiring conscious intent (Gollwitzer, 1999). Prior research has shown that forming an implementation intention leads to immediate and efficient action initiation (e.g., Brandstätter et al., 2001; Gollwitzer \& Brandstätter, 1997). The issue of action initiation without further conscious intent had been addressed only indirectly by Lengfelder and Gollwitzer (2001) who observed that patients with frontal lobe damage still benefit much from forming implementation intentions, and by Webb and Sheeran (2007) who observed that implementation intentions lead to faster lexical decision responses to a word describing the goal-directed behavior specified in the then-component of an implementation intention when the critical cue was presented subliminally. In contrast, the present studies directly measured action preparation and action initiation without further conscious intent. We observed that the subliminal presentation of the critical situation suffices to facilitate the preparation and initiation of the intended goal-directed behavior. A flash of the critical situation that did not allow its conscious perception managed to trigger the preparation of the planned response (Study 1) as well as its actual initiation (Study 2).

Future research should address conditions that moderate effects of implementation intentions on automatic action initiation (Sheeran, Webb, \& Gollwitzer, 2005). For instance, the strength of activation of the superordinate goal should determine whether implementation intentions manage to trigger the initiation of the goaldirected behavior automatically. Moreover, there should be at least a moderate to high level of commitment to the superordinate goal intention to allow implementation intentions to initiate goal-directed action without further conscious intent. A further moderator of the effects might be the commitment to enact the implementation intention (see Achtziger et al., under review). Finally, certain groups of people may not benefit from forming implementation intentions in terms of 
automating goal-directed behaviors as they may not strongly commit to assigned or self-created if-then plans (e.g., Powers, Koestner, \& Topciu, 2005).

Considering the fact that implementation intentions initiate goal-directed behavior even if the critical cue is presented subliminally, one may wonder whether implementation intentions might undermine performance when flexible goal pursuit is required (Gollwitzer, Parks-Stamm, Jaudas, \& Sheeran, 2008). First, action control by implementation intentions could be rigid in the sense that goal striving fails to take into account the activation and strength of the goal intentions. However, several studies have shown that effects of implementation intentions only emerge when participants hold strong goal intentions (e.g., Sheeran, Webb, \& Gollwitzer, 2005 , Study 1), and only when the given situation activates the respective goal intention (Cohen et al., 2008). A second aspect of potential rigidity concerns whether implementation intention participants refrain from using alternative good opportunities to act toward the goal by insisting to act only when the specified situation is encountered. However, when implementation intention participants are offered a favorable opportunity that is not specified in the if-component, they seem to have no problem with using this opportunity as well (Gollwitzer et al., 2008). It appears, then, that the strategic automaticity of implementation intentions is very high in terms of flexibility as they are formed in the service of superordinate goals.

\section{REFERENCES}

Aarts, H., Dijksterhuis, A., \& Midden, C. (1999). To plan or not to plan? Goal achievement or interrupting the performance of mundane behaviors. European Journal of Social Psychology, 29, 971-979.

Achtziger, A., Bayer, U. C., \& Gollwitzer, P. M. (under review). Committing to implementation intentions: Attention and memory effects for selected situational cues.

Achtziger, A., \& Gollwitzer, P. M. (2008). Motivation and volition during the course of action. In J. Heckhausen \& H. Heckhausen (Eds.), Motivation and action (pp. 277-302). London: Cambridge University Press.

Achtziger, A., Gollwitzer, P. M., \& Sheeran, P. (2008). Implementation intentions and shielding goal striving from unwanted thoughts and feelings. Personality and Social Psychology Bulletin, 34, 381-393.

Bargh, J. A. (1990). Auto-motives: Preconscious determinants of social interaction. In $\mathrm{E}$. T. Higgins \& R. M. Sorrentino (Eds.), Handbook of motivation and cognition: Foundations of social behavior (Vol. 2, pp. 93-130). New York: Guilford.
Bargh, J. A. (2006). What have we been priming all these years? On the development, mechanisms, and ecology of nonconscious social behaviour. European Journal of Social Psychology, 36, 147-168.

Bargh, J. A., \& Chartrand, T. L. (2000). The mind in the middle: A practical guide to priming and automaticity research. In H. T. Judd \& M. C. Reis (Eds.), Handbook of research methods in social and personality psychology (pp. 253-285). New York: Cambridge University Press.

Bargh, J. A., Gollwitzer, P. M., Lee-Chai, A., Barndollar, K., \& Trötschel, R. (2001). The automated will: Nonconscious activation and pursuit of behavioral goals. Journal of Personality and Social Psychology, 81, 1014-1027.

Bayer, U.C., \& Gollwitzer, P. M. (2007). Boosting scholastic test scores by will power: The role of implementation intentions. Self and Identity, 6, 1-19.

Brandstätter, V., Lengfelder, A., \& Gollwitzer, P. M. (2001). Implementation intentions and efficient action initiation. Journal of Personality and Social Psychology, 81, 946-960. 
Cohen, A.-L., Bayer, U.C., Jaudas, A., \& Gollwitzer, P. M. (2008). Self-regulatory strategy and executive control: Implementation intentions modulate task switching and Simon task performance. Psychological Research, 72, 12-26.

Csikszentmihalyi, M. (2000). Flow. In A. E. Kazdin (Ed.), Encyclopedia of psychology (Vol. 3, pp. 381-382). Washington, DC: APA.

Eimer, M., \& Schlaghecken, F. (2003). Response facilitation and inhibition in subliminal priming. Biological Psychology, 64, 7-26.

Förster, J., Liberman, N., \& Friedman, R.S. (2007). Seven principles of goal activation: A systematic approach to distinguishing goal priming from priming of non-goal constructs. Personality and Social Psychology Review, 11(3), 211-233.

Gawrilow, C., \& Gollwitzer, P. M. (2008). Implementation intentions facilitate response inhibition in ADHD children. Cognitive Therapy and Research, 32, 261-280.

Gollwitzer, P. M. (1993). Goal achievement: The role of intentions. In W. Stroebe \& M. Hewstone (Eds.), European review of social psychology (Vol. 4, pp. 141-185). Chichester, UK: Wiley.

Gollwitzer, P. M. (1999). Implementation intentions: Strong effects of simple plans. American Psychologist, 54, 493-503.

Gollwitzer, P. M., \& Bargh, J. A. (2005). Automaticity in goal pursuit. In A. Elliot \& C. Dweck (Eds.), Handbook of competence and motivation (pp. 624-646). New York: Guilford.

Gollwitzer, P. M., \& Brandstätter, V. (1997). Implementation intentions and effective goal pursuit. Journal of Personality and Social Psychology, 73, 186-199.

Gollwitzer, P. M., Parks-Stamm, E. J., Jaudas, A., \& Sheeran, P. (2008). Flexible tenacity in goal pursuit. In J. Shah \& W. Gardner (Eds.), Handbook of motivation science. New York: Guilford.

Gollwitzer, P. M., \& Sheeran, P. (2006). Implementation intentions and goal achievement: A meta-analysis of effects and processes. Advances in Experimental Social Psychology, 38, 69-119.

Holland, R. W., Aarts, H., \& Langendam, D. (2006). Breaking and creating habits on the working floor: A field experiment on the power of implementation intentions. Journal of Experimental Social Psychology, 42, 776-783.

Lengfelder, A., \& Gollwitzer, P. M. (2001). Reflective and reflexive action control in patients with frontal brain lesions. Neuropsychology, 15, 80-100.

Lieberman, H. R., \& Pentland, A. P. (1982). Microcomputer-based estimation of psychophysical thresholds: The best PEST. Behavior Research Methods and Instrumentation, 14, 21-25.

Miller, D. T. (2001). Disrespect and the experience of injustice. Annual Review of Psychology, 52, 527-553.

Moskowitz, G.B. (2009). The compensatory nature of goal pursuit: From explicit action to implicit cognition. In G.B. Moskowitz and H. Grant (Eds.), The psychology of goals (pp. 304-336). New York: Guilford.

Parks-Stamm, E. J., Gollwitzer, P. M., \& Oettingen, G. (2007). Action control by implementation intentions: Effective cue detection and efficient response initiation. Social Cognition, 25, 248-266.

Powers, T. A., Koestner, R., \& Topciu, R. A. (2005). Implementation intentions, perfectionism, and goal progress: Perhaps the road to hell is paved with good intentions. Personality and Social Psychological Bulletin, 31, 902-912.

Sheeran, P., Webb, T. L., \& Gollwitzer, P. M. (2005). The interplay between goal intentions and implementation intentions. Personality and Social Psychology Bulletin, 31, 87-98.

Webb, T. L., \& Sheeran, P. (2007). How do implementation intentions promote goal attainment? A test of component processes. Journal of Experimental Social Psychology, 132, 249-268. 
Copyright of Social Cognition is the property of Guilford Publications Inc. and its content may not be copied or emailed to multiple sites or posted to a listserv without the copyright holder's express written permission. However, users may print, download, or email articles for individual use. 